\title{
Occupational Stress and Coping Behaviours Among Dentists in Kerman, Iran
}

Shiva Pouradeli, ${ }^{1}$ Arash Shahravan, ${ }^{2}$ Ali Eskandarizdeh, ${ }^{3}$ "Forozan Rafie, ${ }^{1}$ Maryam A. Hashemipour ${ }^{1}$

$$
\text { الإجهاد المهني وسلوكيات التأقلم بين أطباء الأسنان في كرمان، إيران }
$$

شيفا بوراديلي، اراش شارافان، علي اسكندرزيده، فوروزان رفيع، مريم هاشميبور

ABSTRACT: Objectives: Recognising causes of stress can help prevent associated adverse effects. This study aimed to investigate causes of occupational stress and coping behaviours among general dentists in Iran. Methods: This cross-sectional study was carried out from April to December 2014. A modified version of the Occupational Stress Indicator questionnaire was used to assess causes of stress and coping behaviours among 142 general dentists in Kerman, Iran. Results: A total of 93 dentists participated in the study (response rate: 65.5\%). Of these, 58.9\% reported often being stressed. The mean general stress score was $63.33 \pm 19.99$. The most common causes of stress were maintaining high levels of concentration while working (65.6\%), time pressures (64.5\%), concern over their ability to deliver dental services in future (60.2\%) and rising costs (59.1\%). No significant relationships between stress and gender, age, workplace or working hours per week were noted $(P>0.05)$. However, there was a significant correlation between general stress scores and years of job experience $(P=0.05)$ and number of patients treated daily $(P=0.03)$. The most common methods for coping with stress were resting $(71.0 \%)$, sports $(45.2 \%)$ and entertainment (43.0\%). Most dentists felt that stress management courses could help to reduce stress (89.7\%). Conclusion: General dentists in Kerman were subject to many sources of stress in their workplaces, with significant relationships between stress scores and years of work experience and number of patients treated daily. Dentists should be encouraged to participate in stress management courses to help alleviate stress.

Keywords: Psychological Stress; Dentists; Coping Behavior; Iran.

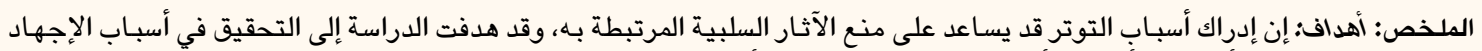

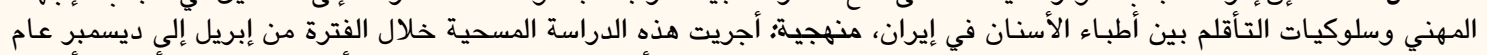

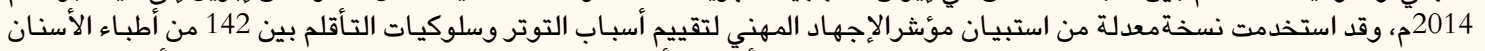

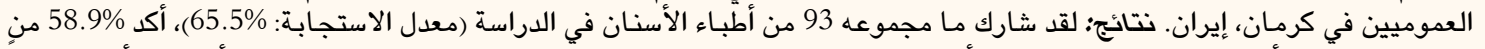

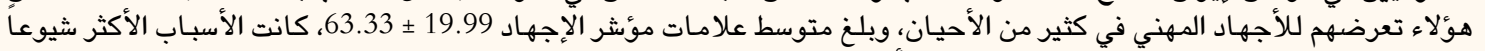

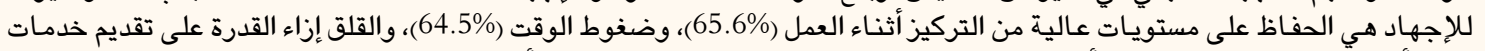

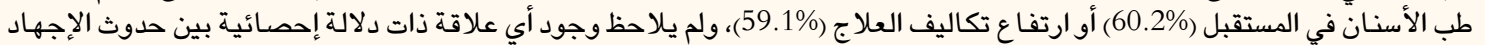

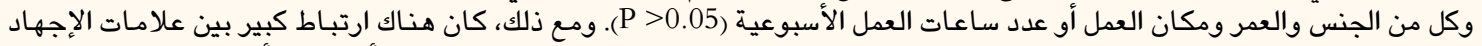

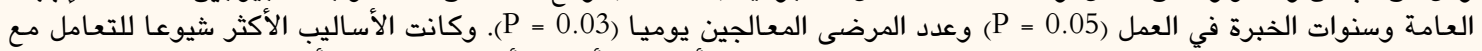

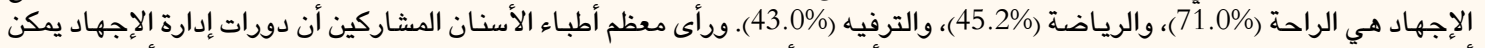

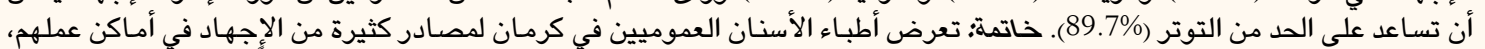



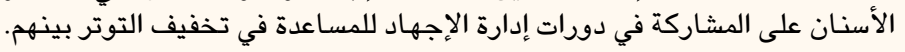

$$
\text { كلمات مفتاحية: الإجهاد النفسي؛ أطباء الأسنان؛ سلوكيات التأقلم؛ إيران. }
$$

\section{ADVANCES IN KNOWLEDGE}

Previous research has shown that dentists lack awareness of stress management strategies. This is the first study from Iran to evaluate sources of job-related stress and coping strategies among general dentists.

\section{Application to Patient Care}

Modern dentistry involves a number of occupational hazards, including high levels of stress. Prolonged stress can have harmful effects, including damage to interpersonal and professional relationships; diminished health and wellbeing; burnout and depression; lowered motivation to engage in work; and low self-esteem.

Successful stress reduction requires that the causes of stress be identified. The results of this study could help researchers in the fields of occupational health, dentistry and psychiatry to develop future interventions to minimise workplace stress among general dentists in Iran. 
$\mathrm{L}$ ONG-TERM EXPOSURE TO STRESS CAN cause physical and psychological problems such as anxiety, depression, cardiovascular diseases, digestive problems, insomnia and headaches. $^{1-3}$ Individuals face occupational stress when there are inconsistencies between the professional requirements of their job and their own strengths, abilities or desires. ${ }^{4}$ Stress can have professional consequences which include absenteeism, reduced productivity and job dissatisfaction, leading in some cases to redundancy or early retirement. ${ }^{5}$ Modern dentistry involves numerous occupational health hazards, including stress, allergic reactions, high noise levels, radiation and musculoskeletal disorders. ${ }^{6,7}$

Dentists face considerable stress at work from dental school onwards. ${ }^{8}$ The development of new and complex technologies, methods and treatment techniques can be an additional source of pressure. Several studies have reported high levels of stress among dentists and many researchers have classified dentistry as a stressful job. ${ }^{5,8,9}$ In a study conducted in the UK by Myers et al., 60\% of dentists reported being nervy, tense or depressed due to work stress. ${ }^{10}$ Cooper et al. indicated that causes of stress among dentists included too little work, administrative difficulties, attempts to establish a practice and dealing with different patients. ${ }^{8}$ In a similar study, Humphris et al. found that sources of occupational stress included treating a high volume of patients, dealing with nervous patients and collecting payment. ${ }^{11}$

Prolonged experiences of stress among dentists can have detrimental effects on interpersonal and professional relationships, as well as on mental and physical health. ${ }^{8}$ For mental health, the consequences can include burnout, depressive disorders, decreased motivation and self-esteem; in contrast, the most commonly reported stress-related physical health issues are lower back pain, increased musculoskeletal complaints, headaches and gastrointestinal problems. ${ }^{12,13}$ Dentists at a higher risk for stress exhibit poorer health and a higher rate of unhealthy behaviours than their less stressed colleagues. ${ }^{9}$ Research has shown that dentists with high stress levels have low awareness of strategies to manage stress. ${ }^{14}$ Before preparing policies for the prevention and management of stress among dental practitioners, it is necessary to identify job-related stressors and available coping strategies. ${ }^{15}$ Recognising sources of stress is important for future prevention and intervention initiatives. Although various surveys have been undertaken to assess stress among general dentists in other regions, no such studies have yet been conducted in Iran. This study therefore aimed to investigate sources of occupational stress and coping strategies among general dentists in Kerman, Iran.

\section{Methods}

This cross-sectional study took place between April and December 2014 among general dentists working in Kerman, Iran. In order for the sample size to be large enough for the results to be statistically significant, all 142 general dentists working in Kerman were invited to participate in the study. General dentists with less than one year of work experience were excluded.

A modified version of the Occupational Stress Indicator questionnaire was used. ${ }^{8}$ The first section of the questionnaire collected demographic information, while the second section consisted of 33 items to assess causes of stress and coping behaviours. Participants rated stressors in terms of their frequency, using the following terms: 'never', 'seldom', 'sometimes', 'often', 'very often' and 'always'. General stress scores were calculated by summing the items. The original English questionnaire was translated into Persian and the internal consistency of the modified and revised questionnaire was assessed using Cronbach's alpha $(\alpha=88 \%)$. Similar questionnaires have been used in different studies all over the world. ${ }^{9,11,16,17}$ The questionnaire was distributed to the participants for self assessment before being collected three days later.

Data were analysed using the Statistical Package for the Social Sciences (SPSS), Version 18 (IBM Corp., Chicago, Illinois, USA). Descriptive statistics were expressed as means, standard deviations and frequencies. A student's t-test was used to compare the effects of variables. The level of significance was defined at $P<0.05$.

This study was approved by the Research Ethics Committee of the Kerman University of Medical Sciences. The aims of the study were explained to all subjects and informed consent was obtained before participation.

\section{Results}

Of the 142 general dentists invited to participate in the study, 93 responded (response rate: 65.5\%). Of these, $58.9 \%$ reported often being stressed. The demographic characteristics of the participants and relationships with general stress scores are presented in Table 1 . The mean general stress score was $63.33 \pm 19.99$. There was no significant relationship between general stress scores and age, gender, workplace or working hours per week. However, general stress scores showed a significant correlation with years of experience $(P=0.05)$ and number of patients treated per day $(P=0.03)$. A post hoc analysis showed that general dentists with less than 10 years of experience exhibited higher stress scores than general dentists who had 
Table 1: Demographic characteristics and general stress scores" among general dentists in Kerman, Iran ( $\mathrm{N}=93)$

\begin{tabular}{lccc} 
Variable & n (\%) & $\begin{array}{c}\text { Mean } \\
\text { stress score } \\
\mathbf{\pm S D}\end{array}$ & P value \\
Gender & & & $\mathbf{0 . 7 7}$ \\
Female & $39(41.9)$ & $64.03 \pm 21.5$ & \\
Male & $54(58.1)$ & $62.83 \pm 18.9$ & \\
\hline
\end{tabular}

Age in years

0.90

$\begin{array}{lrr}<38 & 49(52.7) & 65.31 \pm 18.9 \\ 38-52 & 39(41.9) & 63.21 \pm 20.8 \\ >52 & 5(5.4) & 45.00 \pm 17.6\end{array}$

Place of employment

$\begin{array}{lll}\text { Private clinic } & 59(63.4) & 62.7 \pm 20.5 \\ \text { Government clinic } & 13(14.0) & 67.1 \pm 20.0 \\ \text { Both } & 21(22.6) & 62.5 \pm 18.9\end{array}$

Years of experience

$\begin{array}{lcc}<10 & 50(53.8) & 65.98 \pm 18.9 \\ 10-20 & 34(36.6) & 63.35 \pm 21.3 \\ >20 & 9(9.7) & 48.56 \pm 15.1\end{array}$

Number of patients treated per day

$0.03^{+}$

$\begin{array}{lll}<12 & 72(77.4) & 61.49 \pm 19.5 \\ >12 & 21(22.6) & 74.38 \pm 18.4\end{array}$

Working hours per week

$\begin{array}{lcc}<20 & 26(28.0) & 62.62 \pm 19.8 \\ 20-40 & 59(63.4) & 61.68 \pm 20.0 \\ >40 & 8(8.6) & 57.83 \pm 24.7\end{array}$

$S D=$ standard deviation

*Assessed using a modified version of the Occupational Stress Indicator questionnaire. ${ }^{8}$ Significant at $P<0.05$.

more than 20 years of experience; the mean difference was statistically significant $(P=0.05)$. In addition, general dentists who treated fewer than 12 patients per day had lower stress scores compared with general dentists who treated more than 12 patients per day $(P=0.03)$.

Dentists working in the public sector were more stressed by a lack of patient appreciation while those working in the private sector identified undesirable auxiliary help as a source of stress. The most common sources of stress were maintaining high levels of concentration during working hours (65.6\%), time pressures $(64.5 \%)$, concern over their ability to provide dental services in future (60.2\%) and rising costs (59.1\%). Common stressors identified as occurring very often or always are presented in Table 2. The
Table 2: Common stressors* among general dentists in Kerman, Iran ( $\mathrm{N}=93)$

\begin{tabular}{|c|c|}
\hline Stressor & n (\%) \\
\hline $\begin{array}{l}\text { Maintaining high levels of concentration } \\
\text { during working hours }\end{array}$ & $61(65.6)$ \\
\hline Time pressures & $60(64.5)$ \\
\hline $\begin{array}{l}\text { Concern over their ability to provide dental } \\
\text { services in future }\end{array}$ & $56(60.2)$ \\
\hline Rising costs & $55(59.1)$ \\
\hline Earning enough money to meet lifestyle needs & $49(52.7)$ \\
\hline Quoting fees/collecting payments & $45(48.4)$ \\
\hline Supply of dentists & 44. (47.3) \\
\hline $\begin{array}{l}\text { Unsatisfactory laboratory service from } \\
\text { technicians }\end{array}$ & $43(46.2)$ \\
\hline Coping with difficult patients & $40(43.0)$ \\
\hline Repetitive nature of work & $39(41.9)$ \\
\hline Conflict between profit and professional ethics & $35(37.6)$ \\
\hline Cancellations/no-shows & $33(35.5)$ \\
\hline Equipment breakdown/defective materials & $33(35.5)$ \\
\hline Decisions about future career direction & $31(33.3)$ \\
\hline Possible contraction of viral infections & $31(33.3)$ \\
\hline Long working hours & $31(33.3)$ \\
\hline Working with children & $30(32.3)$ \\
\hline Finding time for family and friends & $29(31.2)$ \\
\hline Causing pain & $29(31.2)$ \\
\hline Treating extremely nervous patients & $25(26.9)$ \\
\hline Lack of patient appreciation & $24(25.8)$ \\
\hline Unsatisfactory auxiliary help & $24(25.8)$ \\
\hline Staff-related problems & $23(24.7)$ \\
\hline Inability to meet own expectations/standards & $22(23.7)$ \\
\hline $\begin{array}{l}\text { Seeing more patients for income-related } \\
\text { reasons }\end{array}$ & $21(22.6)$ \\
\hline Feeling isolated & $20(21.5)$ \\
\hline Making mistakes & $18(19.4)$ \\
\hline Medical emergencies during surgery & $16(17.2)$ \\
\hline Possibility of making mistakes & $15(16.1)$ \\
\hline Perceived problems with colleagues & $14(15.1)$ \\
\hline Feeling underrated by patients & $13(14.0)$ \\
\hline
\end{tabular}

"Stressors identified as occurring 'very often' or 'always'.

most common coping strategies used were resting (71.0\%) and playing sports (45.2\%). The least common strategies were smoking (4.3\%) and consumption of alcohol (1.1\%) [Figure 1]. A total of $89.7 \%$ of participants felt that completing stress management 


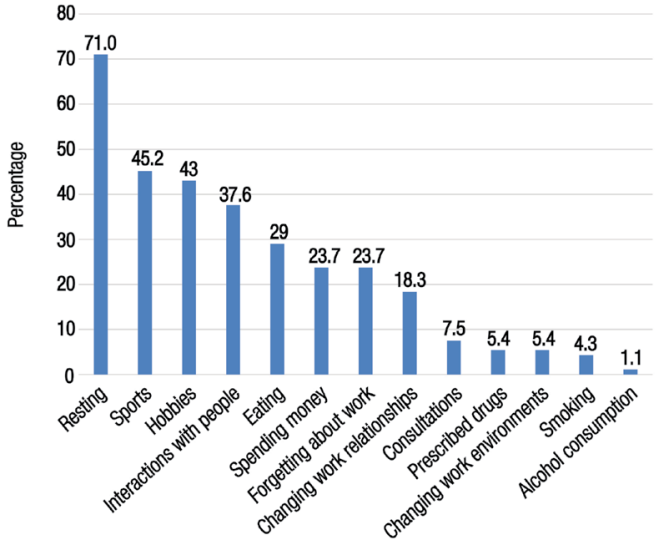

Figure 1: Strategies for coping with stress among general dentists in Kerman, Iran $(\mathrm{N}=93)$.

courses during their graduate studies would have helped them to manage and reduce their stress.

\section{Discussion}

Stress has widely documented physical and psychological consequences, such as anxiety, burn-out and the development of cardiovascular diseases., ${ }^{5,10,18,19}$ Previous studies have shown that dentistry can be a stressful occupation; ${ }^{20,21}$ research on the sources of this stress may be able to assist early prevention and intervention initiatives. This study aimed to study sources of stress and strategies for managing stress among general dentists in Kerman. In the current study, $58.9 \%$ of the dentists surveyed suffered from stress. Similar results have been reported in studies of general dentists in the UK (68.4\%), dentists in Denmark (59.7\%) and orthodontists in Morocco (44\%). 10,17,20

The most common stressors among general dentists in the current study were maintaining concentration, constant time pressures, concern over their ability to provide dental services in future and rising costs. Ayers et al. reported consistent findings, in which the second and third most common sources of stress among general dentists in New Zealand were time-related pressure (48\%) and the need to maintain high levels of concentration at work (43\%); however, the most common source of stress was treating uncooperative children (52\%). ${ }^{22}$ Similarly, the most common sources of stress among general dentists in the UK involved treating difficult or uncooperative patients (64.8\%), continuous time pressures (64.4\%) and constraints imposed by the National Health Service (46.2\%). ${ }^{5}$ Kay et al. also reported that the most common stressors at work among UK dental practitioners consisted of demands made by patients (75\%), problems associated with practice management and staff (56\%) and fears relating to complaints and litigation (54\%). ${ }^{12}$ In a study of dentists in Islamabad, Pakistan, finding enough time for family and friends was reported as the most common source of stress. ${ }^{13}$ Cooper et al. indicated that time management problems were a common source of stress among dentists. ${ }^{8}$ In the current study, constant time pressures were also identified as a major source of stress; these pressures may lead to difficulties with time management and staying on schedule. This findings is consistent with previous research. ${ }^{1,5,11,14}$ Time constraints may be a cause of stress for dentists due to the pressure to schedule as many appointments as possible or perhaps because it impinges on time with family or on other non-work-related interests. However, in contrast to the population surveyed in the present study, dentists in other studies have shown less concern about their ability to work and provide dental services in future. ${ }^{11,22}$

No significant differences were observed between males and females in the current study with regards to occupational stress. This finding mirrored a study in Yemen which reported no statistical differences in stress among men and women. ${ }^{3}$ However, Rogers et al. reported that female Irish dentists were more stressed than males. ${ }^{23}$ In the present study, there was no statistically significant difference in stress scores between younger and older dentists. However, dentists with fewer than 10 years of experience exhibited higher stress scores than dentists with over 20 years of experience. Previous studies have similarly indicated that experience is a factor in controlling and managing stress. ${ }^{8,23}$ This could be attributed to reduced practical and clinical experience, a heightened fear of making mistakes and a lack of familiarity with patients..$^{23,24}$ Additionally, dentists in the present study who treated fewer than 12 patients per day had lower stress scores compared to those who treated more than 12 patients per day. This could be because of the additional patient load resulting in longer working hours, the increased need for concentration, time pressures, tiredness and the repetitive nature of the work. This finding is consistent with those of Ayers et al., in which time pressures had a significant impact on dentist stress levels. ${ }^{22}$ In the current study, dentists working in the public sector were more stressed by a lack of patient appreciation, while those working in the private sector identified undesirable auxiliary help as a source of stress. However, there was no significant relationship between stress scores and type of workplace, which may be due to the low ratio of public sector to private sector practitioners surveyed. In addition, general stress scores were not associated with hours worked per week. These results contrast with those reported by Ayers et al. ${ }^{22}$ 
The most common techniques for managing stress identified in the current study were resting and engaging in sport activities, while the least commonly used were smoking and alcohol consumption. These findings are consistent with those reported by dentists in New Zealand, who use social interactions (77.3\%), forgetting about work (58.6\%) and engaging in sports $(63.4 \%)$ to manage stress. ${ }^{22}$ Tobacco use as a coping mechanism is similarly low in the UK, with only $8.6 \%$ of dentists reporting that they smoke to manage stress. ${ }^{8}$ Similarly, smoking and drug use were not frequently reported as strategies used by Dutch dentists to manage stress. ${ }^{9}$ A major cause of stress among dentists is a lack of knowledge about managing stress. ${ }^{14,24}$ In the present study, most dentists felt that participation in a stress management course during their studies would have helped them to learn to manage their stress levels. Stress management and coping behaviours should therefore be included in the dental curriculum in order to avoid physical and psychological problems that may occur later as a result of occupational stress. Moreover, workshops, seminars and education programmes on occupational stress for clinical dental staff should be organised periodically.

To the best of the authors' knowledge, the present study is the first to evaluate stress among dentists in Iran. However, the study is limited by its crosssectional nature. In addition, the study focused on the experiences of general dentists and, as a result, it was not possible to generalise conclusions to other branches of dentistry. ${ }^{25}$ Additionally, the response rate of this study was not ideal. In future studies, a larger sample size is recommended as well as the inclusion of general dentists, specialists and other physicians. Psychological and personal characteristics may also have an impact on stress management. ${ }^{26}$ These were not analysed in this study and should be considered in future research.

\section{Conclusion}

This study showed that many general dentists in Kerman face several sources of stress, including time pressures, maintaining high levels of concentration during work hours and rising costs. Therefore, it is recommended that workshops, seminars and education programmes on occupational stress be organised for clinical dental staff periodically. This may help general dentists to manage stress levels and improve their working conditions.

\section{CONFLICT OF INTEREST}

The authors declare no conflicts of interest.

\section{FUNDING}

No funding was received for this study.

\section{ACKNOWLEDGEMENTS}

The authors would like to thank all of the general dentists who participated in this study.

\section{References}

1. Agrawal N, Gupta ND, Bey A, Garg AK, Sharma V. Occupational hazards in modern dentistry: A review. Int J Med Health Res 2014; 1:1-9.

2. Aloha K, Havanen J. Job strain, burnout, and depressive symptoms: A prospective study among dentists. J Affect Disord 2007; 104:103-10. doi: 10.1016/j.jad.2007.03.004.

3. Al-Zubair NM, Al-ak'hali MS, Ghandour IA. Stress among dentists in Yemen. Saudi J Dent Res 2015; 6:140-5. doi: 10.10 16/j.sjdr.2014.09.003

4. Seward JP. Occupational stress. In: LaDou J. Current Occupational \& Environmental Medicine, 3rd ed. New York, USA: McGraw-Hill Medical, 2003. Pp. 603-18.

5. Cooper CL. Dentists under pressure: A social psychological study. In: Cooper CL, Marshall J. White Collar and Professional Stress. Chichester, UK: John Wiley \& Sons, 1980. Pp. 3-17.

6. Dalband M, Nasab AF. Evaluation of stress-inducing factors of educational environment in Hamadan Dentistry School's students. Sci J Hamadan Univ Med Sci 2007; 13:48-52.

7. Denton DA, Newton JT, Bower EJ. Occupational burnout and work engagement: A national survey of dentists in the United Kingdom. Br Dent J 2008; 11;205:E13. doi: 10.1038/ sj.bdj.2008.890.

8. Cooper CL, Watts J, Kelly M. Job satisfaction, mental health, and job stressors among general dental practitioners in the UK. Br Dent J 1987; 162:77-81. doi: 10.1038/sj.bdj.4806030.

9. Gorter RC, Eijkman MA, Hoogstraten J. Burnout and health among Dutch dentists. Eur J Oral Sci 2000; 108:261-7. doi: 10.1034/j.1600-0722.2000.108004261.x.

10. Myers HL, Myers LB. 'It's difficult being a dentist': Stress and health in the general dental practitioner. Br Dent J 2004; 197:89-93. doi: 10.1038/sj.bdj.4811476.

11. Humphris GM, Cooper CL. New stressors for GDPs in the past ten years: A qualitative study. Br Dent J 1998; 185:404-6. doi: 10.1038/sj.bdj.4809826.

12. Kay EJ, Lowe JC. A survey of stress levels, self-perceived health and health-related behaviours of UK dental practitioners in 2005. Br Dent J 2008; 204:E19. doi: 10.1038/sj.bdj.2008.490.

13. Khan A, Alvi H, Qadeer S, Khan A, Khan KI, Khan NS. The prevalence of stress and associated factors in dentists working at Islamic International Dental College Hospital, Islamabad. Pak Oral Dent J 2010; 30;521-5.

14. Bourassa M, Baylard JF. Stress situations in dental practice. J Can Dent Assoc 1994; 60:65-7.

15. Lehto TU, Helenius HY, Alaranta HT. Musculoskeletal symptoms of dentists assessed by a multidisciplinary approach. Community Dent Oral Epidemiol 1991; 19:38-44. doi: 10.1111/ j.1600-0528.1991.tb00103.x.

16. Möller AT, Spangenberg JJ. Stress and coping amongst South African dentists in private practice. J Dent Assoc S Afr 1996; 51:347-57.

17. Moore R, Brødsgaard I. Dentists' perceived stress and its relation to perceptions about anxious patients. Community Dent Oral Epidemiol 2001; 29:73-80. doi: 10.1034/j.16000528.2001.00011.x 
18. Newbury-Birch D, Lowry RJ, Kamali F. The changing patterns of drinking, illicit drug use, stress, anxiety and depression in dental students in a UK dental school: A longitudinal study. $\mathrm{Br}$ Dent J 2002; 192:646-9. doi: 10.1038/sj.bdj.4801448.

19. Newton JT, Mistry K, Patel A, Patel P, Perkins M, Saeed K, et al. Stress in dental specialists: A comparison of six clinical dental specialties. Prim Dent Care 2002; 9:100-4. doi: 10.13 08/135576102322492954.

20. Ousehal L, Lazrak L, Hassani K. Evaluation of stress among 100 Moroccan orthodontists. Open J Stomatol 2011; 1:1-6. doi: 10.4236/ojst.2011.11001.

21. Rada RE, Johnson-Leong C. Stress, burnout, anxiety and depression among dentists. J Am Dent Assoc 2004; 135:788-94. doi: 10.14219/jada.archive.2004.0279.

22. Ayers KM, Thomson WM, Newton JT, Rich AM. Job stressors of New Zealand dentists and their coping strategies. Occup Med (Lond) 2008; 58:275-81. doi: 10.1093/occmed/kqn014.
23. Rogers C, Malone KM. Stress in Irish dentists: Developing effective coping strategies. J Ir Dent Assoc 2009; 55:304-7.

24. Brake HT, Gorter R, Hoogstraten J, Eijkman M. Burnout intervention among Dutch dentists: Long-term effects. Eur J Oral Sci 2001; 109:380-7. doi: 10.1034/j.1600-0722.2001. 00086.x.

25. Wilson RF, Coward PY, Capewell J, Laidler TL, Rigby AC, Shaw TJ. Perceived sources of occupational stress in general dental practitioners. Br Dent J 1998; 184:499-502. doi: 10.1038/ sj.bdj.4809674.

26. Gomathi KG, Ahmed S, Sreedharan J. Causes of stress and coping strategies adopted by undergraduate health professions students in a university in the United Arab Emirates. Sultan Qaboos Univ Med J 2013; 13:437-41. 